\title{
A Rare Case of Non-compaction Cardiomyopathy in an Indo-Caribbean Patient
}

\author{
N Taklalsingh ${ }^{1}, \mathrm{M} \mathrm{Chin}^{2}$, T Cummings ${ }^{2}$
}

\begin{abstract}
Non-compaction cardiomyopathy is a rare form of cardiac disease that presents with symptoms of congestive heart failure, ventricular arrhythmias or thromboembolism. Within the Caribbean setting, there are limited data regarding its existence. We present a case of non-compaction cardiomyopathy, diagnosed by transthoracic echocardiogram and cardiac magnetic resonance imaging, with the use of established criteria. It is interesting to highlight such a condition within the small Caribbean population, especially given its link to heritability and the ease with which it can be mistaken for a dilated cardiomyopathy.
\end{abstract}

Keywords: Cardiomyopathy, echocardiography, heart failure, non-compaction

\section{Un raro caso de cardiomiopatía no compactada en un paciente indo-caribeño}

N Taklalsingh ${ }^{1}, \mathrm{M} \mathrm{Chin}^{2}$, T Cummings ${ }^{2}$

\begin{abstract}
RESUMEN
La miocardiopatía no compactada o espongiforme es una forma rara de enfermedad cardiaca que se presenta con síntomas de insuficiencia cardiaca congestiva, arritmias ventriculares o tromboembolismos. En el entorno caribeño, hay datos limitados sobre su existencia. Presentamos un caso de cardiomiopatía no compactada, diagnosticada mediante ecocardiograma transtorácico y resonancia magnética cardíaca, con el uso de criterios establecidos. Es interesante destacar tal condición dentro de la pequeña población caribeña, especialmente dada su relación con la heredabilidad y la facilidad con la que se le puede confundir con una miocardiopatía dilatada.
\end{abstract}

Palabras clave: Miocardiopatía, ecocardiografía, insuficiencia cardíaca, no compactada

West Indian Med J 2018; 67 (1): 84

\section{INTRODUCTION}

Non-compaction cardiomyopathy is a rare form of cardiac disease that presents with symptoms of congestive heart failure, ventricular arrhythmias or thromboembolism. Within the Caribbean setting, there are limited data regarding its prevalence or documented existence. Investigation is typically with a transthoracic echocardiogram (TTE). However, recent studies have shown benefit in newer techniques such as cardiac magnetic resonance imaging (MRI) and 3D-echocardiography
From: ' $S$ tate University of New York, Downstate Medical Center, Brooklyn, New York, United States of America and ${ }^{2}$ Adult Medicine Department, Ministry of Health, Trinidad and Tobago, West Indies.
Correspondence: Dr N Taklalsingh, State University of New York, Downstate Medical Center, 450 Clarkson Avenue, Brooklyn, NY 11203, United States of America. Email: ntaklalsingh1980@gmail. com 
(1). Management options follow standard treatment of heart failure. It is interesting to highlight such a condition within the small Caribbean population, especially given its link to heritability and the ease with which it can be mistaken for a dilated cardiomyopathy (DCM).

\section{CASE REPORT}

\section{Initial presentation}

A 64-year-old man of East Indian descent with a history of diabetes mellitus for the past 14 years and benign prostatic hyperplasia presented to his general practitioner in 2013 with a one-week history of chest tightness, pedal oedema, exertional dyspnoea, orthopnoea and paroxysmal nocturnal dyspnoea. His initial examination findings were consistent with those of decompensated chronic heart failure. He was subsequently hospitalized, and laboratory investigations revealed a serum creatinine of $1.28 \mathrm{mg} / \mathrm{dL}$ (normal: $0.7-1.4 \mathrm{mg} / \mathrm{dL}$ ), a haemoglobin of $14.8 \mathrm{~g} / \mathrm{dL}$ and a platelet count of $224 \times 10^{9}$ with normal serum electrolytes. Serial serum troponin-I values never increased beyond the upper limit of normal. Liver function tests were normal. An initial TTE revealed a markedly dilated and globally hypokinetic left ventricle (LV), apical thrombus, normal pericardium and a left ventricular ejection fraction [LVEF] (by Simpson's method) of $7 \%$. He was treated with anti-failure medications and subsequently referred to the cardiac outpatient clinic for further workup and management.

He was given an initial diagnosis of a DCM likely secondary to an ischaemic substrate, on the basis of his risk factor profile and presenting symptoms.

\section{Outpatient course}

He underwent a series of diagnostic investigations to aid in determining the aetiology of his condition and subsequent best practice management. His outpatient course was significant for recurrent admissions to hospital for acute decompensated heart failure with fluid overload secondary to medication non-compliance or excess fluid intake. He underwent coronary angiography as part of his workup for DCM that revealed coronary arteries free of significant disease and a dilated LV with a severely depressed ejection fraction of $20 \%$.

On a repeat TTE, a diagnosis of non-compaction cardiomyopathy was made. Large channels were seen in the apex (Fig. 1) with severe impairment of LV systolic function and an ejection fraction of $5-10 \%$. There was global hypokinesia of the LV with a restrictive pathophysiology and trans-mitral flow assessed by the ratio of the early to late ventricular filling velocities (E/A ratio) which was elevated with a value of 2.9. Contrast enhancement confirmed non-compacted segments, with channels visualized in the apices of the LV and the right ventricle [RV] (Fig. 2).

Cardiac MRI was subsequently performed which showed a severe non-ischaemic DCM with bi-ventricular failure and an LVEF of $13 \%$ with features of LV and $\mathrm{RV}$ non-compaction. Left ventricular non-compaction in this patient was reported only in the LV apex (Fig. 3).

A 24-hour ambulatory electrocardiogram recording revealed ventricular bigeminy with no episodes of ventricular tachycardia. The patient was advised on the urgent need for an implantable cardiac defibrillator and bi-ventricular pacing, in addition to the potential for

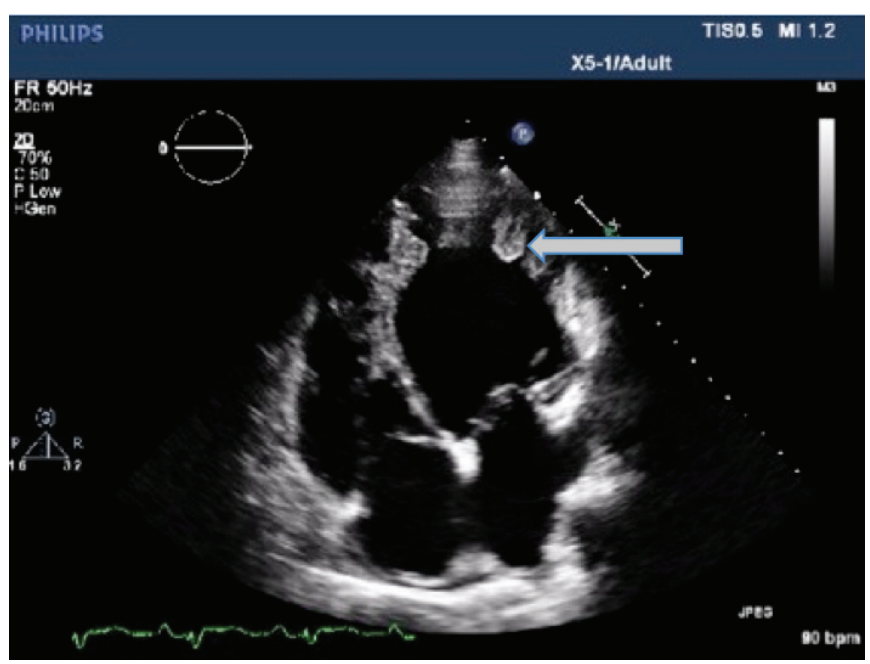

Fig. 1: Our patient's transthoracic echocardiogram showing large channels within the apical portion of the left ventricle (see arrow).

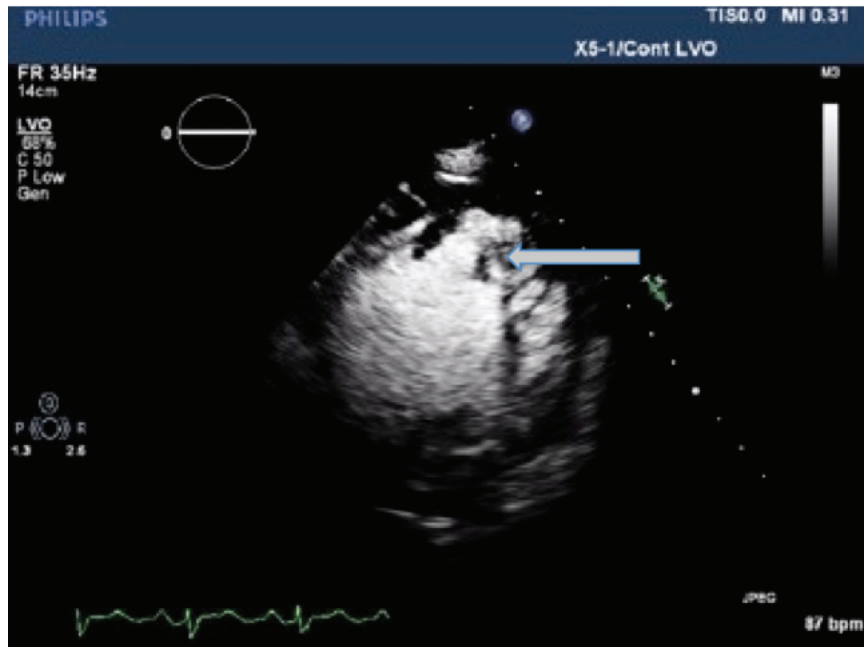

Fig. 2: Contrast study of our patient's transthoracic echocardiogram showing opaque contrast flowing into channels in communication with left ventricular cavity (see arrow). 


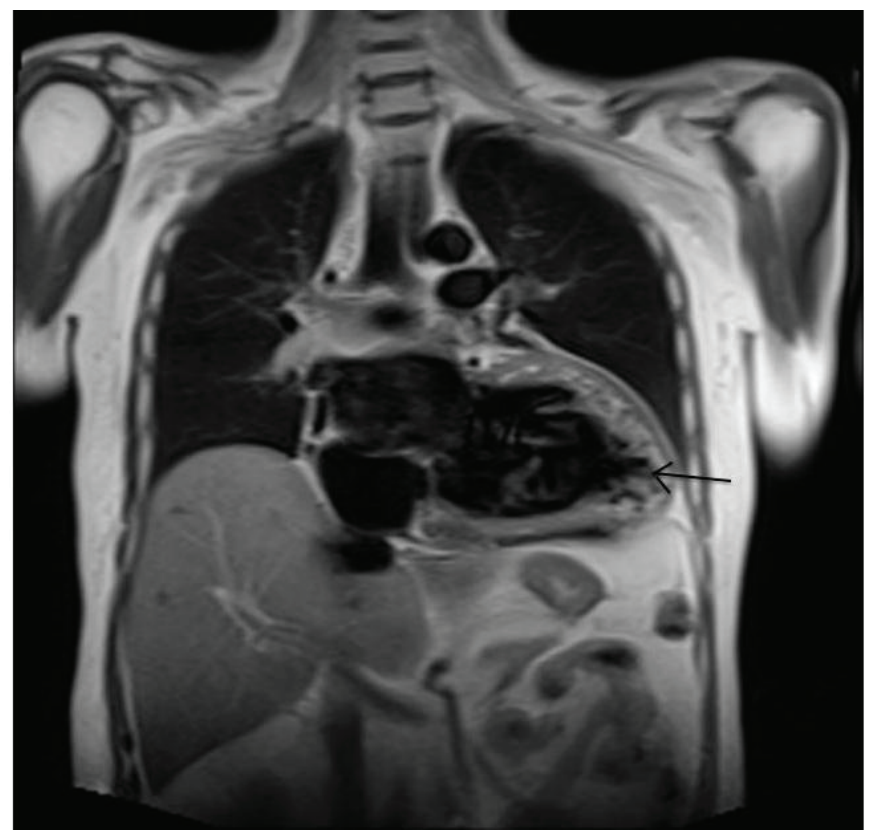

Fig. 3: Presence of non-compaction on cardiac magnetic resonance imaging with delayed gadolinium enhancement showing contrast filling the apical channels of the left ventricle (see arrow)

cardiac transplantation, but he declined to have such interventions performed.

He was managed on standard anti-failure medication and anti-coagulated with warfarin. He received counselling about his prognosis and the need for medication compliance and screening of first-degree relatives for the condition.

\section{DISCUSSION}

Non-compaction cardiomyopathy is characterized by a 'spongy' appearance of the myocardium of the LV. It typically involves the distal apical portions of the

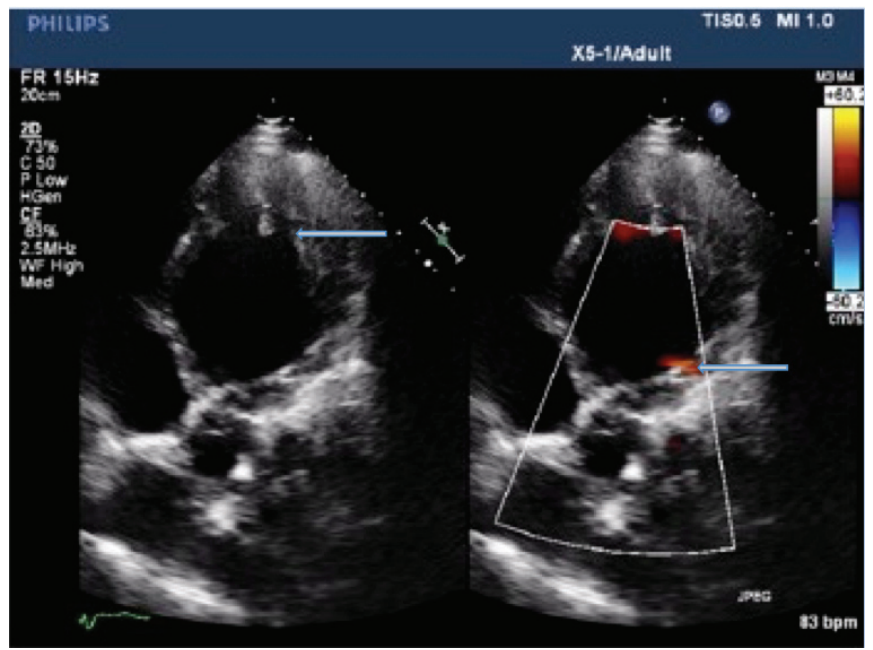

Fig. 4: Connection of inter-trabecular recesses with the left ventricular cavity (see arrows) myocardium of the LV with deep inter-trabecular recesses in communication with the ventricular cavity (Fig. 4). The condition occurs as an isolated disorder of the myocardium or in association with other congenital heart diseases (2).

The true prevalence of non-compaction cardiomyopathy is unknown. One of the first studies regarding its occurrence was documented in 1997, which highlighted only 17 cases of isolated non-compaction of the ventricular myocardium out of 37555 TTEs (3). Its prevalence was estimated at $0.014 \%$ (4) while a systematic review of isolated left ventricular non-compaction (LVNC) reported that prevalence rates may reach $0.14 \%$, with a $65 \%$ male predominance and an average age at diagnosis of 41 years (5). Most studies usually pertain to LVNC, although some case reports have documented the presence of isolated right ventricular non-compaction (RVNC), despite its extremely rare nature (6).

Within the Caribbean, there has been very little evidence of the presence of non-compaction cardiomyopathy. Studies citing the geographic and ethnic distribution of LVNC cases are very rare. Therefore, this practice case may serve to highlight the existence of and the potential need to recognize cases of LVNC as well as RVNC within the Caribbean population.

Non-compaction of the ventricular myocardium is an uncommon finding and is believed to be the result of an arrest in the normal process of endomyocardial morphogenesis during embryonal development (3). However, there has never been any proof of this phenomenon, but studies have shown that a genetic basis for LVNC is present (7). Through sarcomere protein mutations, detected in up to $29 \%$ of cases, there is now an established link between genetic heterogeneity and LVNC. However, the exact mechanism whereby sarcomere mutations lead to abnormal morphogenesis is still unclear, and its association with a clinical phenotype cannot be related (8).

Symptomatology of LVNC is predominantly that of heart failure (9). Of a large reported case series involving 105 patients diagnosed with $\mathrm{LVNC}, 43 \%$ of the patients presented with heart failure, $22 \%$ with cardiac arrhythmias, $8 \%$ with a positive familial screen and $4 \%$ with embolization (9). Of the patients, $46 \%$ had an LVEF of $<30 \%$ at presentation (9). The index case had progressed from New York Heart Association (NYHA) Class II to Class IV heart failure over his seven-year follow-up.

The fundamental diagnostic test utilized in recognizing LVNC is a two-dimensional echocardiogram. Several echocardiographic diagnostic criteria have been formulated over time to aid in this diagnosis. The criteria 
proposed by Jenni et al are widely used, which state that the ratio of non-compacted to compacted $(\mathrm{NC} / \mathrm{C})$ layers of myocardium at end-systole is diagnostic when greater than 2.0 in adults (10), allowing for clear differentiation among hypertrophic cardiomyopathy, DCM and left ventricular hypertrophy. The use of contrast during echocardiography allows for clear endocardial border delineation and better evaluation of almost all segments.

However, the reliability of these criteria is often called into question, with evidence suggesting that they may lead to overestimation of the prevalence of LVNC (11). The advent of 3D echocardiography and cardiac MRI imaging are thus useful tools in diagnosing noncompaction accurately. Cardiac MRI is associated with sensitivity and specificity values of $86 \%$ and $99 \%$, respectively, for the diagnosis of LVNC when an $\mathrm{NC} / \mathrm{C}$ ratio of greater than 2.3:1 is used in diastole [Fig. 5] (12).

In this case, we utilized the $\mathrm{iE} 33$ 3D echocardiography machines, which provided a clear demonstration of the patient's diagnosis in accordance with the criteria proposed by Jenni et al (Figs. 2, 6, 7). Case reports of RVNC have been reported either in isolation or along with LVNC. However, there still remains debate on whether this entity is considered pathological, given the lack of evidence available to distinguish accurately its presence from normal trabeculations within the RV $(3,4)$.

The management of patients with LVNC usually follows the general rules of treatment of chronic heart failure. Patients benefit from early implantation of an implantable cardioverter defibrillator, adjunctive medications with antiarrhythmics and anti-coagulation, although prophylactic anti-coagulation can be advised, given the risk of thrombus formation within the intra-trabecular recesses. Cardiac transplantation is considered an option for patients as a last resort. A clinical practice guideline by the Heart Failure Society of America recommends that at least three generations of families of patients with LVNC be screened with clinical history and investigations (13).

Prognostic outcomes in patients diagnosed with LVNC are variable among studies. A long-term prospective study showed that non-survivors have an increasing presence of NYHA Class III-IV, permanent or persistent atrial fibrillation or an elevated LV end diastolic diameter on presentation (4). The average time to death was $42 \pm 40$ months after diagnosis. Heart failure requiring

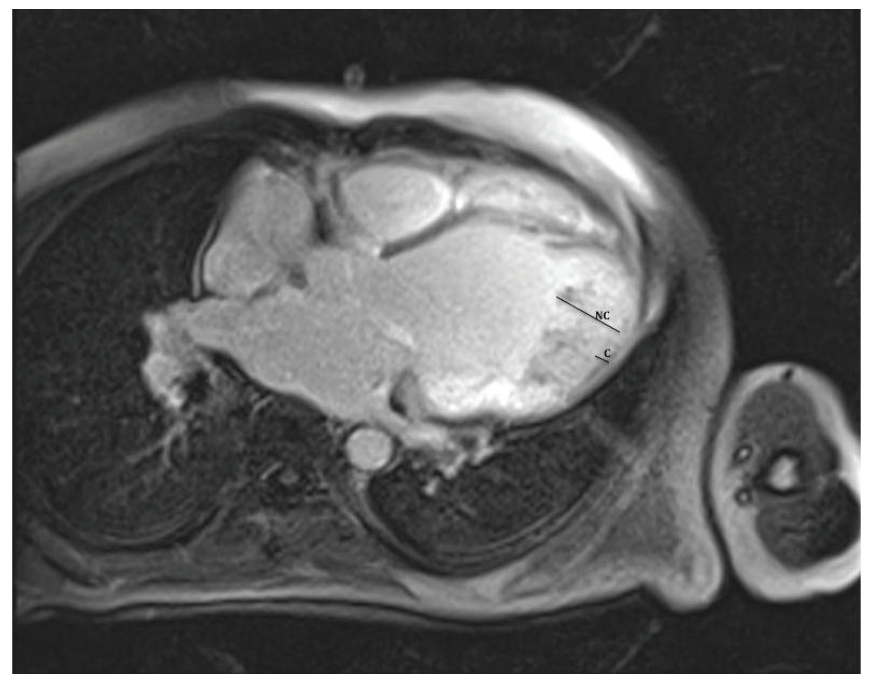

Fig. 5: Presence of prominent trabeculations in the left ventricular apex with a non-compacted to compacted ratio greater than 2.3:1, diagnostic of non-compaction cardiomyopathy on cardiac magnetic resonance imaging (specificity: 99\%).
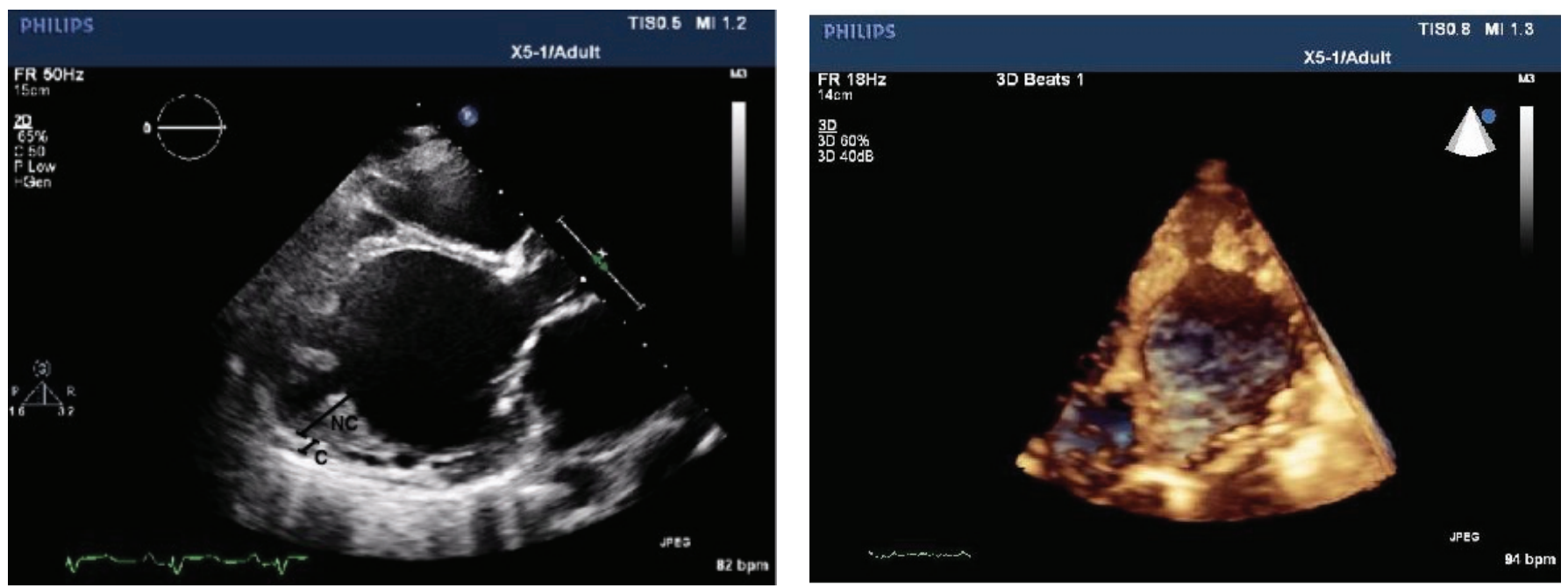

Figs. 6 (left) and 7 (right): Non-compacted left ventricular myocardium and compacted myocardium. It can be seen that the non-compacted to compacted ratio is greater than 2:1 in Fig. 6. Fig. 7 delineates the 3D echocardiographic images of the non-compacted segments. 
hospital admissions, age at diagnosis and gender showed no statistically significant differences between survivors and non-survivors (4). Comparative to other primary genetic cardiomyopathies, LVNC carries a much higher annual mortality rate (5). Our patient's symptomatic state has progressed to that of NYHA Class IV heart failure with an LVEF of 5-10\%, implying a grim outlook. Nonetheless, he is currently in his ninth year since having been diagnosed with LVNC.

\section{CONCLUSION}

In conclusion, non-compaction of the ventricular myocardium is a rare entity. Very few documented cases exist within the Caribbean population in the current literature. Medical practitioners should acknowledge the diagnosis of LVNC and its realistic presence in clinical practice, especially among persons of a Caribbean heritage. Although rare, it certainly bears significance given its potent genetic and heritable predisposition and its ease of being confused with other causes of heart failure, a likely factor contributing to its low incidence. Globally, we should keep an enthusiastic oversight for any upcoming studies regarding the development of this fairly novel and interesting entity.

\section{REFERENCES}

1. Bennett CE, Freudenberger R. The current approach to diagnosis and management of left ventricular noncompaction cardiomyopathy: review of the literature. Cardiol Res Pract 2016; 2016: article ID 5172308.

2. Pantazis AA, Elliott PM. Left ventricular noncompaction. Curr Opin Cardiol 2009; 24: 209-13.
3. Ritter M, Oechslin E, Sutsch G, Attenhofer C, Schneider J, Jenni R. Isolated noncompaction of the myocardium in adults. Mayo Clin Proc 1997; 72: 26-31.

4. Oechslin EN, Attenhofer Jost CH, Rojas JR, Kaufmann PA, Jenni R. Long-term follow-up of 34 adults with isolated left ventricular noncompaction: a distinct cardiomyopathy with poor prognosis. J Am Coll Cardiol 2000; 36: 493-500.

5. Bhatia NL, Tajik AJ, Wilansky S, Steidley DE, Mookadam F. Isolated noncompaction of the left ventricular myocardium in adults: a systematic overview. J Cardiac Fail 2011; 17: 771-8.

6. Choudhary S, Bagarhatta R. Isolated right ventricular non-compaction: a rare form of dilated cardiomyopathy. Journal of Indian College of Cardiology 2015; 5: 98-102.

7. Hoedemaekers YM, Caliskan K, Michels M, Frohn-Mulder I, van der Smagt JJ, Phefferkorn JE et al. The importance of genetic counseling, DNA diagnostics, and cardiologic family screening in left ventricular noncompaction cardiomyopathy. Circ Cardiovasc Genet 2010; 3: 232-9.

8. Probst S, Oechslin E, Schuler P, Greutmann M, Boye P, Knirsch W et al. Sarcomere gene mutations in isolated left ventricular noncompaction cardiomyopathy do not predict clinical phenotype. Circ Cardiovasc Genet 2011; 4: 367-74.

9. Habib G, Charron P, Eicher JC, Giordi R, Donal E, Laperche T et al. Isolated left ventricular non-compaction in adults: clinical and echocardiographic features in 105 patients. Results from a French registry. Eur J Heart Fail 2011; 13: 177-85.

10. Jenni R, Oechslin E, Schneider J, Attenhofer Jost C, Kaufmann PA. Echocardiographic and pathoanatomical characteristics of isolated left ventricular non-compaction: a step towards classification as a distinct cardiomyopathy. Heart 2001; 86: 666-71.

11. Kohli SK, Pantazis AA, Shah JS, Adeyemi B, Jackson G, McKenna WJ et al. Diagnosis of left-ventricular non-compaction in patients with left-ventricular systolic dysfunction: time for a reappraisal of diagnostic criteria? Eur Heart J 2008; 29: 89-95.

12. Petersen SE, Selvanayagam JB, Wiesmann F, Robson MD, Francis JM, Anderson RH et al. Left ventricular non-compaction: insights from cardiovascular magnetic resonance imaging. J Am Coll Cardiol 2005; 46: 101-5.

13. Hershberger RE, Lindenfeld J, Mestroni L, Seidman CE, Taylor MR, Towbin JA et al. Genetic evaluation of cardiomyopathy - a Heart Failure Society of America practice guideline. J Card Fail 2009; 15: 87-97. 